Research Paper

\title{
The impacts of genetic polymorphisms in genes of base excision repair pathway on the efficacy and acute toxicities of (chemo) radiotherapy in patients with nasopharyngeal carcinoma
}

\author{
Jing Wang ${ }^{1,2, *}$, Chengxian Guo ${ }^{3, *}$, Xiaochang Gong ${ }^{1}$, Fan Ao ${ }^{1}$, Yuling Huang ${ }^{1}$, Lihua \\ Huang ${ }^{4}$, Yiqiang Tang ${ }^{1}$, Chunling Jiang ${ }^{1}$, Xiaoxue $X^{2}{ }^{5}$, Qing Dong ${ }^{1,6}$, Min Huang ${ }^{1}$ \\ and Jingao $\mathrm{Li}^{1}$ \\ ${ }^{1}$ Department of Radiation Oncology, Jiangxi Cancer Hospital, Nanchang 330029, China \\ ${ }^{2}$ Department of Intensive Care Unit, Jiangxi Cancer Hospital, Nanchang 330029, China \\ ${ }^{3}$ Center of Clinical Pharmacology, Third Xiangya Hospital, Central South University, Changsha 410013, China \\ ${ }^{4}$ Center for Medical Experiments, Third Xiangya Hospital, Central South University, Changsha 410013, China \\ ${ }^{5}$ Department of Radiation and Oncology, Hunan Provincial Tumor Hospital and Affiliated Tumor Hospital of Xiangya Medical \\ School, Central South University, Changsha 410013, China \\ ${ }^{6}$ Department of Graduate Study, Medical School of Nanchang University, Nanchang 330006, China \\ *These authors have contributed equally to this work \\ Correspondence to: Jingao Li, email: lijingao@hotmail.com \\ Keywords: base excision repair (BER) genes, single nucleotide polymorphism (SNP), nasopharyngeal carcinoma (NPC), acute \\ radiation toxicity, short-term efficacy \\ Received: April 07, $2017 \quad$ Accepted: July 19, $2017 \quad$ Published: August 10, 2017 \\ Copyright: Wang et al. This is an open-access article distributed under the terms of the Creative Commons Attribution License 3.0 \\ (CC BY 3.0), which permits unrestricted use, distribution, and reproduction in any medium, provided the original author and source \\ are credited.
}

\section{ABSTRACT}

Purpose: To explore whether polymorphisms in base excision repair (BER) pathway genes are predictors of (chemo)radiotherapy outcome in patients with nasopharyngeal carcinoma (NPC).

Methods: We genotyped five potentially functional single nucleotide polymorphisms (SNPs) of three genes in the BER pathway in 174 NPC patients who were treated with (chemo)radiotherapy. Sequenom MassArray was used for SNPs analysis. The efficacy at the end of radiotherapy and at 3 months after radiotherapy was evaluated by Response Evaluation Criteria in Solid Tumors (RECIST). Acute radiation toxicity was scored using Radiation Therapy Oncology Group and the European Organization for Research and Treatment of Cancer (RTOG/EORTC) acute radiation morbidity scoring criteria. Logistic regression was employed to assess the multivariate analyses.

Results: We found that the wide genotype GG of X-ray repair cross-complementing 1 (XRCC1) rs25489 (GG vs GA: OR=3.833, 95\%CI=1.512-9.714, $P=0.005$; GG vs $G A+A A$ : $O R=3.610,95 \% C I=1.496-8.713, P=0.004)$ and the wide genotype CC of 8-oxoguanine DNA glycosylase (OGG1) rs1052133 (CC vs GG: OR=0.263, 95\%CI $=0.073-0.951, P=0.042$; CC vs CG+GG: $O R=0.454,95 \% C I=0.195-1.053$, $P=0.066$ ) were positively and negatively associated with primary tumor efficacy at the end of radiotherapy, respectively. By contrast, no association was found between BER gene polymorphisms and the treatment outcomes at 3 months post-treatment or the treatment-related acute toxicities.

Conclusions: The SNPs of the BER genes may act as biomarkers for the curative effect of (chemo)radiotherapy. Further study with long-time follow-up and large population is needed for accurate assessment. 


\section{INTRODUCTION}

Nasopharyngeal carcinoma (NPC) is one of the most common malignant tumors in Southern China [1]. Radiotherapy has long been the mainstay of treatment for patients with loco-regionally confined NPC. The 3-year disease-free survival rate of over $80 \%$ could be achieved after intensity modulated radiation therapy (IMRT) [2]. However, about $20 \%$ of patients still experience either loco-regional or distant treatment failure [2]. The difference of treatment outcomes is partly due to the individual radiosensitivity, especially the ability of DNA damage repair [3-6].

Base excision repair (BER) pathway is the main way to repair the radiation-induced DNA single strand break, including the apurinic/apyrimidinic (AP) site break and DNA base injury [7]. The main enzymes involved in the BER pathway are DNA glycosylase, AP endonuclease, DNA polymerase and DNA ligase [7]. Several key repair genes play important roles in BER pathway, such as the X-ray repair cross-complementing 1 (XRCCl), 8-oxoguanine DNA glycosylase $(O G G 1)$, and apurinic/apyrimidinic endonuclease $1(A P E X I)$ genes, which are associated with human tumor susceptibility and radiation toxicity [8-10]. XRCC1 can connect and fill the DNA incision in the final stage by forming a complex with poly(ADP-ribose) polymerase, DNA ligase III and DNA polymerase $\beta[11]$. OGG1 is a glycosylase that participates in removing oxidatively induced DNA base lesions [12]. And, APEXI can detect and incise the AP sites in the early stage of DNA damage and plays a role in the inflammatory response [13].

Single nucleotide polymorphism (SNP) is a DNA sequence polymorphism caused by single nucleotide change, which could influence the gene expression and protein functions, leading to different susceptibility to disease and affecting the sensitivity of radiotherapy [14-17]. Currently, studies on the association between SNPs of BER pathway genes and radiation reaction were mainly concentrated on breast, prostate and lung cancers [18-20]. XRCC1 rs3213245 (c. $-77 \mathrm{~T}>\mathrm{C}$ ) was associated with grade $\geq 2$ acute skin toxicity in breast cancer patients receiving radiotherapy after breast conserving surgery [18]. In prostate cancer patients treated with radiotherapy, XRCC1 rs25489 (Arg280His) mutation was associated with a lower risk of late bladder and/or rectal toxicity [19]. In patients with non-small cell lung cancer treated with definitive radiation therapy, XRCC1 rs 25487 $(\mathrm{A}>\mathrm{G})$ AA genotype was associated with a lower risk of grade $\geq 2$ radiation pneumonitis, whereas APEX1 rs1130409 $(T>G)$ GG genotype was associated with an increased risk of grade $\geq 2$ radiation pneumonitis in white population [20]. The SNPs of BER pathway genes have been proved to be associated with radiosensitivity. But there were few researches on the relationship between BER pathway gene SNPs and (chemo)radiotherapy efficacy or acute toxicities in NPC patients. From this point, we intend to clarify the impact of the common functional SNPs in BER pathway genes on (chemo)radiotherapy in patients with NPC.

\section{RESULTS}

\section{Population characteristics and genotyping}

The demographic features of the enrolled patients are summarized in Table 1. 174 patients with nasopharyngeal non-keratinizing carcinoma were used for the final analysis, including 118 men and 56 women, with a mean age of 51 years old (ranging from 14-81 years old) at the time of diagnosis. 140 of the 174 patients $(80.5 \%)$ were treated with a combination of radiotherapy and platinum based chemotherapy. The overall stage distribution was $13.8 \%$ (24/174) for stage I-II and $86.2 \%$ (150/174) for stage IIIIV by $7^{\text {th }}$ American Joint Committee on Cancer (AJCC) staging system. There were $116 \mathrm{EBV}$-positive patients and $58 \mathrm{EBV}$-negative patients before treatments. The results of genotypes of 5 SNPs in XRCC1, OGG1 and APEX1 genes of the 174 patients are shown in Table 2. All SNPs were analyzed by Hardy-Weinberg equilibrium. However, the genotype distributions of rs 25487 and rs3213245 were not in accordance with the Hardy-Weinberg equilibrium and excluded in further analysis.

\section{Association between gene polymorphisms and short-term efficacy}

According to the Response Evaluation Criteria in Solid Tumors 1.1 (RECIST 1.1), at the end of radiotherapy, 140 patients (80.5\%) achieved complete remission (CR) of their primary tumors. Of the 144 patients with lymph node metastasis, 125 patients $(86.8 \%)$ had CR of the metastatic nodes. 128 of the 174 patients had complete clinical and imaging information 3 months after radiotherapy, of which $118(92.2 \%)$ had CR in their primary sites, and 97 $(89.8 \%)$ of the 108 patients with node metastases before radiotherapy were in $\mathrm{CR}$ regionally.

After adjusting for potentially prognostic factors, $X R C C 1$ rs25489 and $O G G 1$ rs1052133 had a significant impact on primary tumor efficacy at the end of radiotherapy (Table 3). The likelihood of nonCR was higher in carriers of XRCC1 rs25489 GA and $\mathrm{GA}+\mathrm{AA}$ genotypes than that of $\mathrm{GG}$ genotype $(\mathrm{OR}=3.833$, $95 \% \mathrm{CI}=1.512-9.714, P=0.005$; $\mathrm{OR}=3.610,95 \% \mathrm{CI}=1.496$ 8.713, $P=0.004$; respectively). Patients with $O G G 1$ rs1052133 GG and CG+GG had a lower risk of non$\mathrm{CR}$ than that with $\mathrm{CC}(\mathrm{OR}=0.263,95 \% \mathrm{CI}=0.073-0.951$, $P=0.042 ; \mathrm{OR}=0.454,95 \% \mathrm{CI}=0.195-1.053, P=0.066$ ).

No relationship between SNPs and the treatment efficacy at 3 months after radiotherapy was found in our research (Table 4).

\section{Association between gene polymorphisms and acute radiation toxicity}

According to the Radiation Therapy Oncology Group and the European Organization for Research and Treatment of Cancer (RTOG/EORTC) acute radiation 
Table 1: General characteristics of patients included in this study

\begin{tabular}{|c|c|}
\hline Characteristics & $n(\%)$ \\
\hline \multicolumn{2}{|l|}{ Gender } \\
\hline male & $118(67.8)$ \\
\hline female & $56(32.2)$ \\
\hline \multicolumn{2}{|l|}{ Age at diagnosis (years) } \\
\hline range & $14-81$ \\
\hline mean $\pm \mathrm{SD}$ & $50.55 \pm 11.72$ \\
\hline \multicolumn{2}{|l|}{ BMI } \\
\hline$<24$ & $115(66.1)$ \\
\hline$\geq 24$ & $59(33.9)$ \\
\hline \multicolumn{2}{|l|}{ Drinking } \\
\hline yes & $44(25.3)$ \\
\hline no & $130(74.7)$ \\
\hline \multicolumn{2}{|l|}{ Smoking } \\
\hline yes & $76(43.7)$ \\
\hline no & $98(56.3)$ \\
\hline \multicolumn{2}{|l|}{ Family history } \\
\hline yes & $24(13.8)$ \\
\hline no & $150(86.2)$ \\
\hline \multicolumn{2}{|l|}{ T stage $^{1}$} \\
\hline $1-2$ & $45(25.9)$ \\
\hline $3-4$ & $129(74.1)$ \\
\hline \multicolumn{2}{|l|}{$\mathrm{N}_{\text {stage }}{ }^{1}$} \\
\hline $0-1$ & $88(50.6)$ \\
\hline $2-3$ & $86(49.4)$ \\
\hline \multicolumn{2}{|l|}{ Clinical stage $\mathrm{e}^{1}$} \\
\hline I-II & $24(13.8)$ \\
\hline III-IV & $150(86.2)$ \\
\hline \multicolumn{2}{|l|}{ Treatment } \\
\hline radiotherapy alone & $34(19.5)$ \\
\hline chemoradiotherapy & $140(80.5)$ \\
\hline \multicolumn{2}{|l|}{ EBV-DNA } \\
\hline negative & $58(33.3)$ \\
\hline positive & $116(66.7)$ \\
\hline
\end{tabular}

${ }^{1}$ Using $7^{\text {th }}$ American Joint Committee on Cancer (AJCC) staging system.

BMI, body mass index; SD, standard deviation; EBV-DNA, plasma Epstein-Barr virus DNA.

morbidity scoring criteria, there were $30,61,65$ and 18 patients who had exhibited radiation-induced mucositis of grade 1, 2, 3 and 4, respectively. As shown in Table 5, no SNP in BER pathway genes were associated with the risk of acute mucositis when severe mucositis $(\mathrm{G} 3+, n=83)$ were compared with moderate or less mucositis (G0-2, $n=91)$.
Acute radiation dermatitis developed in all of the 174 patients, including grade 1 in 128 patients $(73.6 \%)$, grade 2 in 31 patients (17.8\%), and grade 3 in 15 patients $(8.6 \%)$. There was no grade 0 or grade 4 dermatitis observed during the treatment. There were no significant correlation between SNPs in BER pathway genes and 
Table 2: Genotype distribution of 5 SNPs in BER pathway genes

\begin{tabular}{lcccc}
\hline Gene & Polymorphic site & Alleles (wild/mutant) & $\begin{array}{c}\text { Genotype } \\
\text { distribution }\end{array}$ & HWE \\
\hline$X R C C 1$ & $\mathrm{rs} 25487$ & $\mathrm{G} / \mathrm{A}$ & $65 / 95 / 14$ & $\mathbf{0 . 0 1 0}$ \\
$X R C C 1$ & $\mathrm{rs} 25489$ & $\mathrm{G} / \mathrm{A}$ & $129 / 39 / 6$ & 0.170 \\
$X R C C 1$ & $\mathrm{rs} 3213245$ & $\mathrm{~T} / \mathrm{C}$ & $109 / 64 / 1$ & $\mathbf{0 . 0 0 9}$ \\
OGG1 & $\mathrm{rs} 1052133$ & $\mathrm{C} / \mathrm{G}$ & $57 / 83 / 34$ & 0.702 \\
$A P E X 1$ & $\mathrm{rs} 1130409$ & $\mathrm{~T} / \mathrm{G}$ & $68 / 88 / 18$ & 0.176 \\
\hline
\end{tabular}

${ }^{1}$ Wild homozygote / heterozygote / mutant homozygote.

HWE, Hardy-Weinberg equilibrium.

$P$ values $<0.05$ are shown in bold.

Table 3: Multivariate analyses of the correlation between SNPs and treatment efficacy at the end of radiotherapy

\begin{tabular}{|c|c|c|c|c|c|c|c|c|c|c|c|}
\hline \multirow[t]{2}{*}{ SNPs } & \multirow[t]{2}{*}{ Genotypes } & \multicolumn{5}{|c|}{ Primary tumor efficacy $^{1}(n=174)$} & \multicolumn{5}{|c|}{ Lymph node efficacy $^{1}(n=144)$} \\
\hline & & $\mathbf{C R}^{2}$ & Non-CR ${ }^{2}$ & OR & $95 \%$ CI & $P$ & $\mathbf{C R}^{2}$ & Non-CR ${ }^{2}$ & OR & $95 \% \mathrm{CI}$ & $P$ \\
\hline \multirow{4}{*}{$X R C C 1$ rs 25489} & GG:GA & & & 3.833 & $1.512-9.714$ & 0.005 & \multirow{4}{*}{$95 / 26 / 4$} & \multirow{4}{*}{$15 / 4 / 0$} & 0.818 & $0.199-3.358$ & 0.780 \\
\hline & GG:AA & 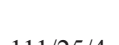 & 10 & 2.552 & $0.360-18.088$ & 0.348 & & & - & - & - \\
\hline & GG:(GA+AA) & $1111 / 20 / 4$ & $10 / 14 / 2$ & 3.610 & $1.496-8.713$ & 0.004 & & & 0.699 & $0.174-2.813$ & 0.615 \\
\hline & $(\mathrm{GG}+\mathrm{GA}): \mathrm{AA}$ & & & 1.764 & $0.257-12.110$ & 0.564 & & & - & - & - \\
\hline \multirow{4}{*}{$O G G 1$ rs 1052133} & CC:CG & \multirow{4}{*}{$42 / 68 / 30$} & \multirow{4}{*}{$15 / 15 / 4$} & 0.552 & $0.227-1.344$ & 0.191 & \multirow{4}{*}{$45 / 58 / 22$} & \multirow{4}{*}{$5 / 9 / 5$} & 1.922 & $0.518-7.128$ & 0.329 \\
\hline & CC:GG & & & 0.263 & $0.073-0.951$ & 0.042 & & & 2.832 & $0.605-13.252$ & 0.186 \\
\hline & $\mathrm{CC}:(\mathrm{CG}+\mathrm{GG})$ & & & 0.454 & $0.195-1.053$ & 0.066 & & & 2.161 & $0.629-7.430$ & 0.221 \\
\hline & $(\mathrm{CC}+\mathrm{CG}): \mathrm{GG}$ & & & 0.371 & $0.114-1.209$ & 0.100 & & & 1.895 & $0.532-6.745$ & 0.324 \\
\hline \multirow{4}{*}{$A P E(X) 1$ rs 1130409} & TT:TG & \multirow{4}{*}{$51 / 74 / 15$} & \multirow{4}{*}{$17 / 14 / 3$} & 0.853 & $0.348-2.088$ & 0.728 & \multirow{4}{*}{$47 / 65 / 13$} & \multirow{4}{*}{$9 / 8 / 2$} & 0.592 & $0.179-1.963$ & 0.392 \\
\hline & TT:GG & & & 0.392 & $0.088-1.749$ & 0.220 & & & 0.698 & $0.107-4.570$ & 0.708 \\
\hline & TT:(TG+GG) & & & 0.719 & $0.310-1.667$ & 0.442 & & & 0.615 & $0.203-1.865$ & 0.390 \\
\hline & $(\mathrm{TT}+\mathrm{TG}): \mathrm{GG}$ & & & 0.420 & $0.099-1.786$ & 0.240 & & & 0.862 & $0.139-5.331$ & 0.873 \\
\hline
\end{tabular}

${ }^{1}$ Adjusted for age, gender, drinking, smoking, family history, BMI, TNM stage, clinical stage, treatment and EBV-DNA.

${ }^{2}$ Wild homozygote / heterozygote / mutant homozygote.

SNPs, single nucleotide polymorphisms; CR, complete remission; OR, odds ratio; 95\%CI, 95\% confidence interval.

$P$ values $<0.05$ are shown in bold.

the severity of radiation dermatitis when G0-1 dermatitis was compared with $\mathrm{G} 2+$ dermatitis after a multivariate adjustment (Table 5).

\section{Relation between radiation dose to specific region and radiation toxicity}

The relation between radiation toxicity and the mean radiation doses to specific organs/tissues, including the oral cavity, larynx, skin and $4 \mathrm{~mm}$ under the skin $\left(\operatorname{skin}_{4 \mathrm{~mm}}\right)$, was investigated in this study. As shown in Table 6, There were no significant differences of radiation dose to the oral cavity (3893.65 \pm 545.20 vs. $3930.05 \pm 551.43, P=0.662)$ and larynx (4215.65 \pm 350.68 vs. $4215.06 \pm 325.32, P=0.991)$ between the patients with G0-2 and G3+ mucositis. On the other hand, radiation doses to the skin (3496.06 \pm 722.31 vs. $3245.97 \pm 583.61, P=0.086)$ and $\operatorname{skin}_{4 \mathrm{~mm}}(3656.47$ \pm 462.32 vs. $3577.97 \pm 475.70, P=0.509)$ were also not significantly different between the patients with G0-1 and $\mathrm{G} 2+$ dermatitis.

\section{DISCUSSION}

In our study, we found that the wide genotype GG of XRCC1 rs25489 and the wide genotype CC of OGG1 rs 1052133 were positively and negatively, respectively, associated with primary tumor efficacy at the end of 
Table 4: Multivariate analyses of the correlation between SNPs and treatment efficacy at 3 months after radiotherapy

\begin{tabular}{|c|c|c|c|c|c|c|c|c|c|c|c|}
\hline \multirow[t]{2}{*}{ SNPs } & \multirow[t]{2}{*}{ Genotypes } & \multicolumn{5}{|c|}{ Primary tumor efficacy ${ }^{1}(n=128)$} & \multicolumn{5}{|c|}{ Lymph node efficacy $^{1}(n=108)$} \\
\hline & & $\mathbf{C R}^{2}$ & Non-CR ${ }^{2}$ & OR & $95 \% \mathrm{CI}$ & $P$ & $\mathbf{C R}^{2}$ & Non-CR ${ }^{2}$ & OR & $95 \% \mathrm{CI}$ & $P$ \\
\hline \multirow{4}{*}{$X R C C 1$ rs 25489} & GG:GA & & & 1.351 & $0.243-7.502$ & 0.731 & \multirow{4}{*}{$71 / 22 / 4$} & \multirow{4}{*}{$8 / 3 / 0$} & 1.150 & $0.225-5.881$ & 0.866 \\
\hline & GG:AA & & & - & - & - & & & - & - & - \\
\hline & GG:(GA+AA) & $84 / 28 / 6$ & $7 / 3 / 0$ & 1.032 & $0.196-5.425$ & 0.970 & & & 1.052 & $0.208-5.310$ & 0.951 \\
\hline & $(\mathrm{GG}+\mathrm{GA}): \mathrm{AA}$ & & & - & - & - & & & - & - & - \\
\hline \multirow{4}{*}{$O G G 1$ rs1052133 } & $\mathrm{CC}: \mathrm{CG}$ & & & 0.535 & $0.122-2.334$ & 0.405 & \multirow{4}{*}{$35 / 44 / 18$} & \multirow{4}{*}{$2 / 5 / 4$} & 1.838 & $0.296-11.401$ & 0.514 \\
\hline & $\mathrm{CC}: \mathrm{GG}$ & & & - & - & - & & & 3.795 & $0.555-25.975$ & 0.174 \\
\hline & $\mathrm{CC}:(\mathrm{CG}+\mathrm{GG})$ & $38 / 58 / 22$ & $6 / 4 / 0$ & 0.335 & $0.079-1.427$ & 0.139 & & & 2.446 & $0.455-13.154$ & 0.297 \\
\hline & $(\mathrm{CC}+\mathrm{CG}): \mathrm{GG}$ & & & - & - & - & & & 2.617 & $0.588-11.656$ & 0.207 \\
\hline \multirow{4}{*}{$A P E(X) 1 \mathrm{rs} 1130409$} & TT:TG & \multirow{4}{*}{$40 / 65 / 13$} & \multirow{4}{*}{$5 / 4 / 1$} & 0.480 & $0.096-2.407$ & 0.372 & \multirow{4}{*}{$32 / 55 / 10$} & \multirow{4}{*}{$5 / 4 / 2$} & 0.574 & $0.118-2.802$ & 0.493 \\
\hline & TT:GG & & & 0.479 & $0.037-6.166$ & 0.572 & & & 1.116 & $0.141-8.859$ & 0.917 \\
\hline & TT:(TG+GG) & & & 0.479 & $0.106-2.166$ & 0.339 & & & 0.702 & $0.171-2.875$ & 0.623 \\
\hline & $(\mathrm{TT}+\mathrm{TG}): \mathrm{GG}$ & & & 0.666 & $0.057-7.756$ & 0.745 & & & 1.375 & $0.184-10.300$ & 0.756 \\
\hline
\end{tabular}

${ }^{1}$ Adjusted for age, gender, drinking, smoking, family history, BMI, TNM stage and clinical stage, treatment and EBV-DNA.

${ }^{2}$ Wild homozygote / heterozygote / mutant homozygote.

SNPs, single nucleotide polymorphisms; CR, complete remission; OR, odds ratio; 95\%CI, 95\% confidence interval.

$P$ values $<0.05$ are shown in bold.

Table 5: Multivariate analyses of the correlation between SNPs and radiation toxicity in NPC patients $(n=174)$

\begin{tabular}{|c|c|c|c|c|c|c|c|c|c|c|c|}
\hline \multirow[t]{2}{*}{ SNPs } & \multirow[t]{2}{*}{ Genotypes } & \multicolumn{5}{|c|}{ Radiation mucositis $^{1}$} & \multicolumn{5}{|c|}{ Radiation dermatitis $^{1}$} \\
\hline & & G0-2 ${ }^{2}$ & G3 $+{ }^{2}$ & OR & $95 \% \mathrm{CI}$ & $P$ & G0-1 ${ }^{2}$ & $\mathrm{G} 2+^{2}$ & OR & $95 \% \mathrm{CI}$ & $P$ \\
\hline \multirow{4}{*}{$X R C C 1$ rs 25489} & GG:GA & \multirow{4}{*}{$68 / 19 / 4$} & \multirow{4}{*}{$61 / 20 / 2$} & 1.222 & $0.572-2.615$ & 0.605 & \multirow{4}{*}{$96 / 27 / 5$} & \multirow{4}{*}{$33 / 12 / 1$} & 1.373 & $0.592-3.184$ & 0.460 \\
\hline & GG:AA & & & 0.517 & $0.082-3.246$ & 0.481 & & & 0.926 & $0.090-9.514$ & 0.948 \\
\hline & GG:(GA+AA) & & & 1.093 & $0.533-2.244$ & 0.808 & & & 1.322 & $0.587-2.979$ & 0.500 \\
\hline & $(\mathrm{GG}+\mathrm{GA}): \mathrm{AA}$ & & & 0.494 & $0.079-3.084$ & 0.451 & & & 0.850 & $0.084-8.625$ & 0.891 \\
\hline \multirow{4}{*}{$O G G 1$ rs1052133 } & $\mathrm{CC}: \mathrm{CG}$ & \multirow{4}{*}{$30 / 40 / 21$} & \multirow{4}{*}{$27 / 43 / 13$} & 1.199 & $0.595-2.414$ & 0.611 & \multirow{4}{*}{$42 / 58 / 28$} & \multirow{4}{*}{$15 / 25 / 6$} & 1.119 & $0.503-2.492$ & 0.782 \\
\hline & CC:GG & & & 0.719 & $0.295-1.753$ & 0.467 & & & 0.521 & $0.172-1.576$ & 0.248 \\
\hline & $\mathrm{CC}:(\mathrm{CG}+\mathrm{GG})$ & & & 1.033 & $0.536-1.993$ & 0.922 & & & 0.910 & $0.426-1.944$ & 0.808 \\
\hline & $(\mathrm{CC}+\mathrm{CG}): \mathrm{GG}$ & & & 0.646 & $0.293-1.423$ & 0.278 & & & 0.487 & $0.179-1.323$ & 0.158 \\
\hline \multirow{4}{*}{$A P E(X) 1 \mathrm{rs} 1130409$} & TT:TG & \multirow{4}{*}{$39 / 45 / 7$} & \multirow{4}{*}{$29 / 43 / 11$} & 1.299 & $0.652-2.586$ & 0.457 & \multirow{4}{*}{$51 / 64 / 13$} & \multirow{4}{*}{$17 / 24 / 5$} & 1.341 & $0.605-2.976$ & 0.470 \\
\hline & TT:GG & & & 1.787 & $0.577-5.538$ & 0.314 & & & 0.875 & $0.234-3.273$ & 0.843 \\
\hline & TT:(TG+GG) & & & 1.379 & $0.716-2.656$ & 0.336 & & & 1.235 & $0.580-2.630$ & 0.584 \\
\hline & (TT+TG):GG & & & 1.569 & $0.535-4.603$ & 0.412 & & & 0.761 & $0.217-2.673$ & 0.670 \\
\hline
\end{tabular}

${ }^{1}$ Adjusted for age, gender, drinking, smoking, family history, BMI, TNM stage and clinical stage, treatment and EBV-DNA.

${ }^{2}$ Wild homozygote / heterozygote / mutant homozygote.

SNPs, single nucleotide polymorphisms; OR, odds ratio; 95\%CI, 95\% confidence interval.

$P$ values $<0.05$ are shown in bold.

radiotherapy. By contrast, no association was found between the BER gene polymorphisms and both tumor responses at 3 months after treatment and treatment related toxicities.
BER pathway gene polymorphisms were reported to be related to the oncogenesis [21-23]. Recent studies also showed that the mutation of BER pathway genes could increase the radiosensivity by reducing the DNA 
Table 6: Comparison of radiation doses between patients with low and high radiation toxicity

\begin{tabular}{|c|c|c|c|c|c|c|c|c|}
\hline & \multicolumn{4}{|c|}{ Radiation mucositis } & \multicolumn{4}{|c|}{ Radiation dermatitis } \\
\hline & \multicolumn{2}{|c|}{ Oral cavity } & \multicolumn{2}{|c|}{ Larynx } & \multicolumn{2}{|c|}{ Skin $^{1}$} & \multicolumn{2}{|c|}{ Skin $_{4 \mathrm{~mm}}{ }^{2}$} \\
\hline & G0-2 & G3+ & G0-2 & G3+ & G0-1 & G2+ & G0-1 & G2+ \\
\hline$n$ & 91 & 83 & 91 & 83 & 86 & 31 & 68 & 20 \\
\hline $\begin{array}{l}\text { Radiation dose } \\
(\text { mean } \pm \mathrm{SD}, \mathrm{cGy})\end{array}$ & $3893.65 \pm 545.20$ & $3930.05 \pm 551.43$ & $4215.65 \pm 350.68$ & $4215.06 \pm 325.32$ & $3496.06 \pm 722.31$ & $3245.97 \pm 583.61$ & $3656.47 \pm 462.32$ & $3577.97 \pm 475.70$ \\
\hline$P$ & 0.662 & & 0.991 & & 0.086 & & 0.509 & \\
\hline
\end{tabular}

repair ability [24]. Costa et al analyzed the association of common polymorphisms in BER pathway genes with the risk and prognosis of oropharyngeal squamous cell carcinoma (OPSCC) [10]. By comparing 200 OPSCC patients with 200 controls, they found that XRCC1 rs $1799782 \mathrm{CT}+\mathrm{TT}$ genotypes $(19.5 \%$ vs $11.0 \%, P=0.04)$ and XRCC1 T-T-G-G (for rs3213245, rs 1799782, rs25489 and rs 25487 ) haplotype (17.5\% vs $10.0 \%, P=0.04)$ were more common in patients with OPSCC than in controls. They also analyzed 125 patients with stage IV disease and found that patients with $O G G 1$ rs1052133 CC genotype had significant shorter progression free survival (PFS) than those with $\mathrm{CG}+\mathrm{GG}$ genotypes $(\mathrm{HR}=1.68, P=0.02)$. Our data showed that patients with the wild genotype CC of OGG1 rs1052133 had a high risk of non-CR of the primary tumors at the end of radiotherapy, which was consistent with Costa et al's research. But there was no association between this SNP and the efficacy at 3 months after radiotherapy. Since there are lots of factors that participate in the damage mechanism of radiation, such as DNA repair after damage, cell proliferation, apoptosis and necrosis, inflammation, and oxidative stress [17]. With the progress of the disease, the influence of the above factors in each phase may be different. Moreover, there had been some patients (46 patients) who withdrew in the process of follow-up, which might be one of the reasons for the inconsistent results. Our study only explored the shortterm efficacy, and the long-term curative effect still needs further follow-up.

Jin et al found that heavy smokers ( $>20$ pack-years) carrying XRCC1 rs25487 GG genotype had significantly lower PFS rates than others in the 75 patients with NPC at stage II-IVA-B $(\mathrm{HR}=2.019,95 \% \mathrm{CI}$ : 1.010-4.036, $P=0.047$ ) [25]. In 60 Chinese patients with locally advanced NPC after radiotherapy, Zhai et al discovered that XRCC1 rs25487 AA was correlated with higher rate of medium-term tumor regression after RT for primary nasopharyngeal neoplasm and metastatic lymph nodes than other two genotypes ( $>80 \%$ vs $40-60 \%, P<0.01$ ) [26]. In our study, XRCC1 rs 25487 was not in accordance with the Hardy-Weinberg equilibrium and thus excluded in further analysis. However, it still needs a large number of samples to validate.

Several studies showed that BER pathway related gene polymorphisms were associated with acute or chronic radiation toxicities in cancer patients. In a study of 101 patients with head and neck squamous cell carcinoma, the development of grade $\geq 2$ mucositis was increased in patients with XRCC1 rs25487 A allele $(\mathrm{HR}=1.72)$ [27]. Alsbeih et al analyzed the association between XRCC1 rs25487 (g.G28152A) and the late reaction to radiotherapy in $60 \mathrm{NPC}$ patients, and found that $X R C C 1$ g.28152A allele was significantly associated with a lower grade condition of grade $\geq 2$ skin and deep tissue fibrosis (OR=0.30, 95\%CI: 0.10-0.89, $P=0.02$ ) [28]. After increasing the sample size to 155 patients, they still found that compared with wild genotypes, patients with $X R C C 1$ rs25487 A allele had a lower risk of grade 3-4 fibrosis [29]. Another research of 114 NPC patients proved that the XRCC1 rs25487 GA genotype was significantly associated with the development of grade 3 dermatitis $(\mathrm{OR}=2.65,95 \% \mathrm{CI}=1.04-6.73, P=0.037)$ and was also associated with higher incidence of grade 3 mucositis with a borderline statistical significance $(\mathrm{OR}=2.11$, $95 \% \mathrm{CI}=0.951-4.66, P=0.065$ ) [30]. However, Zhai et al did not find any association between XRCC1 rs25487 and acute or chronic radiation toxicities in 60 patients with locally advanced NPC [26]. We did not find any BER gene polymorphism that has significant impact on acute radiation toxicity reaction in NPC patients. This may be because that the radiation damage to normal tissues, such as skin and mucosa damage, depends mainly on cell regeneration, proliferation and inflammation, while the role of DNA damage repair is relatively small.

We didn't find any relations between the mean dose to the oral cavity and skin and radiation mucositis or dermatitis. One reason is that the prescribed doses to the normal tissues were strictly limited, and the radiation doses to the normal tissues were only slightly different among this cohort of patients. An other reason for this paradoxical result is the inaccuracy of delineation of the normal tissues. There was often compromise in the 
contouring of normal tissues if the tumor was close to or even invaded the normal tissues. In this case, only the tissues not involved by tumors were contoured and protected in an effort to best treat the tumors, and the mean dose to the normal tissues could be under-estimated.

In summary, our study explored the impact of polymorphisms in BER pathway genes on (chemo) radiotherapy in NPC patients. We only found the BER SNPs had significant correlation with the curative effect at the end of radiation therapy and did not find any influence on radiation toxicity. Further study with long-time follow-up and large population would be needed to explain the relevance between polymorphisms and the long-term survival.

\section{MATERIALS AND METHODS}

\section{Patient selection and treatment}

A total of 174 NPC patients were recruited into our research between April 2014 and September 2015 in Jiangxi Cancer Hospital, China, according to the inclusion and exclusion criteria. Patients were included in the study if they had pathologically confirmed non-keratinizing NPC if they met all of the following criteria: no distant metastasis at diagnosis; previously untreated of their tumors; ECOG performance status score $\leq 1$; no severe comorbilities of heart, lung, liver or kidney. Lactating femal patients or patients with pregnancy, patients with active infections before treatment and history of any other tumors were excluded from the study. The study protocol was approved by the Ethics Committee of Jiangxi Cancer Hospital and registered online through the website of Chinese Clinical Trial Registry (ChiCTR-OPC-14005257). All eligible patients signed the informed consent before treatment.

All the patients were treated by radiotherapy with $6 \mathrm{MV}$ photons by use of intensity-modulated radiation therapy (IMRT). The radiation techniques were reported elsewhere [31]. Briefly, the prescription doses were 70 Gy in 30 to 33 fractions to the primary tumors, 66 to 70 Gy in 30 to 33 fractions to the positive cervical lymph nodes, and 54 to $60 \mathrm{~Gy}$ in 30 to 33 fractions to other areas with potential tumor involvement. All radiotherapies were delivered once daily, 5 days a week. 34 of the 174 patients were treated by radiotherapy alone, while other patients received a combination of radiotherapy and platinumbased chemotherapy.

Demographic and clinical data, such as age, gender, smoking and drinking status, TNM stage (using $7^{\text {th }}$ AJCC staging system), MRI and nasopharyngoscope information, were recorded. Those who had smoked $>100$ cigarettes in their lifetime were considered "smoker", and all others were considered "non-smoker" [32]. "Drinker" was defined as a daily ethanol intake $>40 \mathrm{~g}$ for men and $>20 \mathrm{~g}$ for women [33]. Additionally, the mean doses to the oral cavity, larynx, skin and $4 \mathrm{~mm}$ under the skin $\left(\operatorname{skin}_{4 \mathrm{~mm}}\right)$ in the radiotherapy plans were also collected.

\section{Study end points}

Acute radiation toxicity was evaluated from the first day to the end of radiotherapy. In our study, radiation-induced mucositis and dermatitis were evaluated and scored according to RTOG/EORTC acute radiation morbidity score criteria $[34,35]$. Patients with high grade of toxicity were compared with patients with low toxicity.

The efficacy at the end of radiotherapy and at 3 months after radiotherapy was evaluated by RECIST 1.1 $[34,36]$ based on MRI imaging and nasopharyngoscope. The RECIST 1.1 defines the efficacy with complete remission (CR), partial remission (PR), stable disease (SD) and progression disease (PD). The primary tumor efficacy is only for the tumor. In this study, we divided all patients into two groups: CR or non-CR.

\section{SNP selection and genotyping analysis}

The National Center for Biotechnology Information dbSNP database (http://www.ncbi.nlm.nih.gov/) and HapMap database (http://hapmap.ncbi.nlm.nih.gov/) were used to identify the potentially functional SNPs based on the following 3 criteria: 1) location in the promoter untranslated region or coding region of gene; 2) a minor allele frequency $(\mathrm{MAF}) \geq 10 \%$ in Han Chinese reported in the dbSNP database; 3 ) previous reports of an association with radiosensitivity in NPC or other cancers. According to the candidate gene approach, a total of 5 SNPs in 3 BER pathway genes were genotyped, including XRCC1 (rs25487, rs25489 and rs3213245), OGG1 (rs1052133) and $A P E X 1$ (rs1130409).

Peripheral venous blood $(3 \mathrm{ml})$ was collected from patients before radiotherapy and stored at $-20^{\circ} \mathrm{C}$. Genomic DNA was extracted from the blood lymphocytes using a Wizard ${ }^{\circledR}$ Genomic DNA Purification Kit (Promega, America) according to the manufacturer's instructions. All the DNA samples were stored at $-80^{\circ} \mathrm{C}$ until genotyping analysis. Sequenom MassArray (BioMiao Biological, Beijing, China) was used for SNPs analysis.

\section{Statistical analysis}

Statistical analysis was performed using SPSS 18.0 software (IBM, Armonk, New York, USA) and $P<0.05$ was considered significant. The patients' characteristics, including gender, age, body mass index (BMI), smoking history, drinking history, family history, TNM stage, use of chemotherapy and EBV, were chosen as adjusting factors for multivariate analysis. The multivariate analysis of the association between SNPs and radiation toxicity or shortterm efficacy was estimated by computing the odds ratio (OR) and 95\% confidence interval $(95 \% \mathrm{CI})$ from logistic regression analyses. 


\section{ACKNOWLEDGMENTS}

This research was supported by the National Natural Science Foundation of China (No.81460409 and No.81301942) and the New Xiangya Talent Project of the Third Xiangya Hospital of Central South University (JY201505).

\section{CONFLICTS OF INTEREST}

The authors have declared that no competing interests exist.

\section{REFERENCES}

1. Kamran SC, Riaz N, Lee N. Nasopharyngeal carcinoma. Surg Oncol Clin N Am. 2015;24:547-561.

2. Zhang Y, Chen M, Chen C, Kong L, Lu JJ, Xu B. The efficacy and toxicities of intensive induction chemotherapy followed by concurrent chemoradiotherapy in nasopharyngeal carcinoma patients with $\mathrm{N} 3$ disease. 2017:7:3668.

3. Safwat A, Bentzen SM, Turesson I, Hendry JH. Deterministic rather than stochastic factors explain most of the variation in the expression of skin telangiectasia after radiotherapy. Int $\mathrm{J}$ Radiat Oncol Biol Phys. 2002;52:198-204.

4. Hornhardt S, Rossler U, Sauter W, Rosenberger A, Illig T, Bickeboller H, Wichmann HE, Gomolka M. Genetic factors in individual radiation sensitivity. DNA Repair (Amst). 2014;16:54-65.

5. Banin S, Moyal L, Shieh S, Taya Y, Anderson CW, Chessa L, Smorodinsky NI, Prives C, Reiss Y, Shiloh Y, Ziv Y. Enhanced phosphorylation of $\mathrm{p} 53$ by ATM in response to DNA damage. Science. 1998;281:1674-1677.

6. Nishioka A, Ogawa Y, Kubonishi I, Kataoka S, Hamada $\mathrm{N}$, Terashima M, Inomata T, Yoshida S. An augmentation of Fas (CD95/APO-1) antigen induced by radiation: flow cytometry analysis of lymphoma and leukemia cell lines. Int J Mol Med. 1999;3:275-278.

7. Hubenak JR, Zhang Q, Branch CD, Kronowitz SJ. Mechanisms of injury to normal tissue after radiotherapy: a review. Plast Reconstr Surg. 2014;133:49e-56e.

8. Karahalil B, Bohr VA, Wilson DM 3rd. Impact of DNA polymorphisms in key DNA base excision repair proteins on cancer risk. Hum Exp Toxicol. 2012;31:981-1005.

9. Bartsch H, Dally H, Popanda O, Risch A, Schmezer P. Genetic risk profiles for cancer susceptibility and therapy response. Recent Results Cancer Res. 2007;174:19-36.

10. Costa EF, Santos ES, Liutti VT, Leal F, Santos VC, Rinck-Junior JA, Mariano FV, Coutinho-Camillo CM, Altemani A, Lima CS, Lourenco GJ. Association between polymorphisms in genes related to DNA baseexcision repair with risk and prognosis of oropharyngeal squamous cell carcinoma. J Cancer Res Clin Oncol. 2016;142:1917-1926.

11. Caldecott KW. XRCC1 and DNA strand break repair. DNA Repair (Amst). 2003;2:955-969.

12. Robertson AB, Klungland A, Rognes T, Leiros I. DNA repair in mammalian cells: base excision repair: the long and short of it. Cell Mol Life Sci. 2009;66:981-993.

13. Tell G, Fantini D, Quadrifoglio F. Understanding different functions of mammalian AP endonuclease (APE1) as a promising tool for cancer treatment. Cell Mol Life Sci. 2010;67:3589-3608.

14. Ching A, Caldwell KS, Jung M, Dolan M, Smith OS, Tingey S, Morgante M, Rafalski AJ. SNP frequency, haplotype structure and linkage disequilibrium in elite maize inbred lines. BMC Genet. 2002;3:19.

15. Guo Z, Shu Y, Zhou H, Zhang W, Wang H. Radiogenomics helps to achieve personalized therapy by evaluating patient responses to radiation treatment. Carcinogenesis. 2015;36:307-317.

16. Weng L, Zhang L, Peng Y, Huang RS. Pharmacogenetics and pharmacogenomics: a bridge to individualized cancer therapy. Pharmacogenomics. 2013;14:315-324.

17. Guo CX, Wang J, Huang LH, Li JG, Chen X. Impact of single-nucleotide polymorphisms on radiation pneumonitis in cancer patients. Mol Clin Oncol. 2016;4:3-10.

18. Terrazzino S, La Mattina P, Masini L, Caltavuturo T, Gambaro G, Canonico PL, Genazzani AA, Krengli M. Common variants of eNOS and XRCC1 genes may predict acute skin toxicity in breast cancer patients receiving radiotherapy after breast conserving surgery. Radiother Oncol. 2012;103:199-205.

19. Langsenlehner T, Renner W, Gerger A, Hofmann G, Thurner EM, Kapp KS, Langsenlehner U. Association between single nucleotide polymorphisms in the gene for $\mathrm{XRCC} 1$ and radiation-induced late toxicity in prostate cancer patients. Radiother Oncol. 2011;98:387-393.

20. Yin M, Liao Z, Liu Z, Wang LE, Gomez D, Komaki R, Wei Q. Functional polymorphisms of base excision repair genes $\mathrm{XRCC} 1$ and APEX1 predict risk of radiation pneumonitis in patients with non-small cell lung cancer treated with definitive radiation therapy. Int J Radiat Oncol Biol Phys. 2011;81:e67-73.

21. Liu HX, Li J, Ye BG. Correlation between gene polymorphisms of CYP1A1, GSTP1, ERCC2, XRCC1, and XRCC 3 and susceptibility to lung cancer. Genet Mol Res. 2016;15.

22. Wu WQ, Zhang LS, Liao SP, Lin XL, Zeng J, Du D. Association between XRCC1 polymorphisms and laryngeal cancer susceptibility in a Chinese sample population. Genet Mol Res. 2016;15.

23. Wang X, Ma KW, Zhao YG, Wang GJ, Li W. XRCC1 rs25487 polymorphism is associated with lung cancer risk in epidemiologically susceptible Chinese people. Genet Mol Res. 2015;14:15530-15538. 
24. Niu Y, Zhang X, Zheng Y, Zhang R. XRCC1 deficiency increased the DNA damage induced by gamma-ray in HepG2 cell: involvement of DSB repair and cell cycle arrest. Environ Toxicol Pharmacol. 2013;36:311-319.

25. Jin H, Xie X, Wang H, Hu J, Liu F, Liu Z, Zhou J, Zhang Y, Xi X, Hu B, Liao Y, Tang J. ERCC1 Cys8092Ala and XRCC1 Arg399Gln polymorphisms predict progressionfree survival after curative radiotherapy for nasopharyngeal carcinoma. PLoS One. 2014;9:e101256.

26. Zhai XM, Hu QC, Gu K, Wang JP, Zhang JN, Wu YW. Significance of XRCC1 Codon399 polymorphisms in Chinese patients with locally advanced nasopharyngeal carcinoma treated with radiation therapy. Asia Pac J Clin Oncol. 2016;12:e125-132.

27. Pratesi N, Mangoni M, Mancini I, Paiar F, Simi L, Livi L, Cassani S, Buglione M, Grisanti S, Almici C, Polli C, Saieva C, Magrini SM, et al. Association between single nucleotide polymorphisms in the XRCC1 and RAD51 genes and clinical radiosensitivity in head and neck cancer. Radiother Oncol. 2011;99:356-361.

28. Alsbeih G, Al-Harbi N, Al-Hadyan K, El-Sebaie M, Al-Rajhi N. Association between normal tissue complications after radiotherapy and polymorphic variations in TGFB1 and XRCC1 genes. Radiat Res. 2010;173:505-511.

29. Alsbeih G, El-Sebaie M, Al-Harbi N, Al-Hadyan K, Shoukri $\mathrm{M}$, Al-Rajhi N. SNPs in genes implicated in radiation response are associated with radiotoxicity and evoke roles as predictive and prognostic biomarkers. Radiat Oncol. 2013;8:125.

30. Li H, You Y, Lin C, Zheng M, Hong C, Chen J, Li D, Au WW, Chen Z. XRCC1 codon 399Gln polymorphism is associated with radiotherapy-induced acute dermatitis and mucositis in nasopharyngeal carcinoma patients. Radiat Oncol. 2013;8:31.
31. Li JG, Yuan X, Zhang LL, Tang YQ, Liu L, Chen XD, Gong XC, Wan GF, Liao YL, Ye JM, Ao F. A randomized clinical trial comparing prophylactic upper versus whole-neck irradiation in the treatment of patients with node-negative nasopharyngeal carcinoma. Cancer. 2013;119:3170-3176.

32. Wen J, Liu H, Wang Q, Liu Z, Li Y, Xiong H, Xu T, Li P, Wang LE, Gomez DR, Mohan R, Komaki R, Liao Z, et al. Genetic variants of the LIN28B gene predict severe radiation pneumonitis in patients with non-small cell lung cancer treated with definitive radiation therapy. Eur J Cancer. 2014;50:1706-1716.

33. Kai K, Koga H, Aishima S, Kawaguchi A, Yamaji K, Ide $\mathrm{T}$, Ueda J, Noshiro H. Impact of smoking habit on surgical outcomes in non-B non-C patients with curative resection for hepatocellular carcinoma. World J Gastroenterol. 2017;23:1397-1405.

34. Guo XB, Ma WL, Liu LJ, Huang YL, Wang J, Huang LH, Peng XD, Yin JY, Li JG, Chen SJ, Yang GP, Wang H, Guo CX. Effects of gene polymorphisms in the endoplasmic reticulum stress pathway on clinical outcomes of chemoradiotherapy in Chinese patients with nasopharyngeal carcinoma. Acta Pharmacol Sin. 2017;38:571-580.

35. Du L, Zhang XX, Feng LC, Chen J, Yang J, Liu HX, Xu SP, Xie CB, Ma L. Treatment of nasopharyngeal carcinoma using simultaneous modulated accelerated radiation therapy via helical tomotherapy: a phase II study. Radiol Oncol. 2016;50:218-225.

36. Eisenhauer EA, Therasse P, Bogaerts J, Schwartz LH, Sargent D, Ford R, Dancey J, Arbuck S, Gwyther S, Mooney M, Rubinstein L, Shankar L, Dodd L, et al. New response evaluation criteria in solid tumours: revised RECIST guideline (version 1.1). Eur J Cancer. 2009;45:228-247. 